\title{
Nas entrelinhas do Cambridge Handbook of Social Representations: aplicações de um domínio teórico para a educação
}

\author{
Between the lines at The Cambridge Handbook of Social \\ Representations: usages of a theoretical domain for education
}

\section{SAMMUT, Gordon et al. (Ed.). The Cambridge Handbook of Social Representations. Cambridge: Cambridge University Press, 2015. 481 p.}

O lançamento do The Cambridge Handbook of Social Representations motivou a elaboração de três perguntas direcionadas a uma das autoras que contribuíram para a obra, com vistas a debater o potencial da Teoria das Representaçóes Sociais (TRS) para a Educação. O livro, que foi organizado em quatro seções, de modo a abarcar as fundaçóes da teoria, os desenvolvimentos conceituais, as novas orientaçóes e as aplicaçóes no campo da história, da ciência política, da sustentabilidade, dos estudos religiosos e da saúde, constitui uma importante contribuição, sobretudo porque, como salientam os editores, a despeito de os aspectos nucleares da TRS terem sido debatidos ao longo de mais de meio século, muitos se mantêm incompreendidos.

No contexto brasileiro, as pesquisas educacionais que recorrem ao instrumental teórico ofertado pela TRS são numerosas ${ }^{2}$. No entanto, dada a tradição anglosaxônica nesse âmbito teórico, o referido Handbook não contemplou precisamente a aplicação desse domínio da Psicologia Social para os estudos em Educação,

1 Doutora em Educação: Psicologia da Educação (PUC-SP), Coordenadora do Centro Internacional de Estudos em Representações Sociais e Subjetividade - Educação. Pesquisadora da Fundação Carlos Chagas. Vice-coordenadora do Programa de Mestrado Profissional Formação de Gestores Educacionais, Docente do Programa de Mestrado em Educação da UNICID. Rua Quitanduba, 363, São Paulo. (11) 3723-3003.

2 A exemplo das produçóes decorrentes dos projetos abrigados pelo Centro Internacional de Estudos em Representações Sociais e Subjetividade - Educação (CIERS-ed), da Fundação Carlos Chagas.

R. Educ. Públ.

Cuiabá

v. 27

n. 64

p. $277-282$

jan./abr. 2018 
o que motivou a entrevista realizada com Caroline Howarth ${ }^{3}$, psicóloga social e professora do Department of Psychological and Behavioural Science - The London School of Economics and Political Science, que, além de participar da obra $^{4}$, vêm desenvolvendo pesquisas em escolas inglesas.

Adelina Novaes: A sua pesquisa em escolas reitera o potencial da TRS de cruzar fronteiras disciplinares e contribuir para o campo educacional. Como você vê as possibilidades de a Psicologia Social contribuir para uma abordagem transdisciplinar em educação?

Caroline Howarth: Se você olha para as preocupaçóes de professores e educadores, o que frequentemente se torna aparente é a necessidade de relacionar disciplinas, uma vez que não é possível a uma única disciplina proporcionar todas as respostas. No entanto, você verá também que há, muitas vezes, aspectos psicológicos envolvidos, porque, na educação, a relação professor-aluno e o diálogo com o conhecimento que ocorre em uma sala de aula, bem como o conhecimento que circula na sociedade são importantes. Questóes acerca do pertencimento (quantos estudantes sentem-se realmente pertencentes a uma classe e a uma comunidade escolar ou a comunidade na qual ela está localizada) e questóes sobre identidade são peças-chave em educação. Há ainda questóes sobre como as relações intergrupos são administradas, no que se refere ao fato de que nós viemos de diferentes lugares e diferentes culturas. Nós temos meninas e meninos estudando juntos, nós temos pessoas de diferentes religiôes. Há sempre diferentes grupos em uma sala de aula e isso tem que ser gerido de maneira bastante sensível e construtiva com vistas a evitar dinâmicas destrutivas, como estereótipos em relação às meninas, às pessoas de diferentes religióes, ou em relação às pessoas de certa comunidade, ou com deficiência. Portanto, relaçôes intergrupo, representaçóes de diferentes grupos, identificação, pertença, diálogo e relacionamento, todos esses elementos são centrais na educação e na interação que ocorre no contexto escolar. Eles também são centrais para a Psicologia Social e estudados pela Sociologia e pelo campo das políticas públicas. Todas as ciências sociais têm algo de bastante importante a nos dizer. O campo da educação tem estudado todas essas temáticas. Há também, frequentemente, um chamado para

3 Entrevista realizada em julho de 2015, em Londres, Reino Unido. Agradeço a Marli Palomares Tombara e Marli Herrera, pela degravação e à Margarete May Berkenbrock Rosito pela revisão da versão transcrita em inglês que serviu de base para a tradução.

4 Caroline Howarth escreveu em parceria com Flora Cornish e Alex Gillespie o capítulo Making community: diversity, movement and interdependence (p. 179-190). 
olhar os processos psicológicos envolvidos. Portanto, eu penso que, para entender muitas das diferentes problemáticas nas escolas e na educação, nós temos que ter uma abordagem interdisciplinar. Eu penso que a TRS, como uma teoria bastante particular da Psicologia, é deveras útil aqui. Algumas pessoas podem afirmar bastante explicitamente que a TRS é uma teoria que conecta a Sociologia à Psicologia porque ela tem um forte foco em história, cultura, em sociedade como um todo. Ela se interessa menos em como os indivíduos pensam, ou como os indivíduos desenvolvem certas atitudes, e está mais interessada nas conexôes entre as formas de pensar dos indivíduos. Moscovici, o fundador e desenvolvedor da TRS, a descreveu como uma antropologia de mais de uma cultura. E há muitas maneiras pelas quais nós podemos ver a TRS se conectando à antropologia, bem como às outras ciências humanas. Para mim, provavelmente porque o meu trabalho tem focado bastante nas escolas, o campo educacional tem sido um importante terreno para pensar sobre como desenvolver e como utilizar a TRS.

Adelina Novaes: Ao considerarmos que os professores educam as novas geraçôes, e tendo em conta os processos de identidade-alteridade entre professores e estudantes, quais seriam as relaçóes entre baixa autoestima de professores e a manutenção de ciclos de discriminação?

Caroline Howarth: Nos meus primeiros estudos, na minha pesquisa doutoral, eu estava muito atenta às maneiras pelas quais algumas representaçóes de grupos minoritários de estudantes (a exemplo dos estudantes negros britânicos) se transformavam em ciclos autorrealizadores, nos quais os professores tinham uma expectativa negativa dos estudantes, que eles não teriam sucesso, não teriam bom desempenho, e que seriam muito desordeiros em sala de aula. Existe uma enorme quantidade de pesquisas em educação, em uma diversidade de contextos, que indicam isso, que mostram ciclos de racismo e poder sobre estereótipos raciais, tornando-se algo como uma profecia autorrealizadora. Teorias feministas, como a de bell hooks, cujo trabalho em representaçóes é muito diferente dos da TRS, mas onde há ecos, mantêm alguns pontos de conexão que eu penso que são muito reveladores, muito importantes, em termos de desenvolvimento de uma compreensão mais crítica do papel do poder nos processos de representação. É muito evidente que essas representaçóes podem se tronar cíclicas ou autorrealizadoras. O que você está me perguntando é algo ligeiramente diferente, algo muito importante, sobre a identidade dos próprios professores, sobre a autoestima dos professores, da confiança dos docentes e como isso pode desenvolver um significante papel em ciclos de insucesso. Isso merece uma análise cuidadosa. Em alguns estudos, especialmente em Sociologia da Educação no Reino Unido, houve uma tendência em se pensar sobre as vias pelas quais alguns professores podem desempenhar estereótipos negativos, segundo uma ideia de que alguns professores eram racistas e outros não. Para 
mim, isso é bastante preocupante porque individualiza o problema, e esse é um problema societal. O problema refere-se às representaçóes de grupos minoritários, representações sobre o estudante negro, mas refere-se também às representaçóes de professores e sobre as formas pelas quais a profissão docente é construída e entendida. Para voltar para a questão que você formulou sobre agência ${ }^{5}$, eu acredito que nós poderíamos pensar muito mais sobre oportunidades para os professores se tornarem eles mesmos agentes nesse processo e pensar sobre as formas nas quais as ansiedades acerca de seus próprios desempenhos, suas próprias expectativas sobre diferentes grupos de alunos, podem se tornar parte do problema. Mas isso tem que ser feito com verdadeira delicadeza, porque esse bastante individualizado tipo de assumpção é encontrado em alguns contextos europeus. Significa dizer que o problema é de alguns professores, e não de todos os professores. Eu penso que isso náo ajuda, que apenas pode deixar os professores mais ansiosos. Melhor seria se nós encontrássemos maneiras de pensar sobre os processos institucionais para empoderar os professores e permitir que eles encontrem o espaço e os recursos para criar um diálogo e um relacionamento mais positivo com os seus alunos, e pensar sobre as formas pelas quais os professores precisam ser apoiados para fazer isso.

Adelina Novaes: Você tem dedicado atenção às formas de promoção de mudança social. Como você analisa tal possibilidade?

Caroline Howarth: Nós costumeiramente dizemos contexto ${ }^{6}$, mas nem sempre definimos bem o significado desse termo. Perguntamos o que temos que olhar para o contexto local, nas interaçóes particulares entre professores e alunos, e para o contexto da comunidade: o que está acontecendo em uma parte particular de Londres, ou em uma cidade particular do norte da Inglaterra, etc. Então, nós temos que olhar para o contexto histórico político e social mais amplo para entender a significância e a relevância de diferentes ideias e sistemas de discursos sobre pertença - quem pertence, quem não pertence, quem é britânico, quem não é, tudo isso está associado a um contexto mais amplo. Uma das coisas que argumentamos é que, de um lado nós não podemos ser tão ingênuos ou tão otimistas para pensar que as escolas têm a habilidade, os recursos, ou a exclusiva responsabilidade de mudar elementos estruturais em um nível amplo. Isso seria realmente impossível, mas, ao mesmo tempo, nós estivemos imensamente

5 Agency, no original.

6 A entrevistada faz referência ao debate constante em: Howarth, Caroline; Andreouli, Eleni. 'Changing the context': tackling discrimination at school and in society. International Journal of Educational Development, 41, 2015. p. 184-191. Disponível em: <http://www.sciencedirect.com/science/article/pii/ S0738059314000510>. Acesso em: 1 set. 2016. 
encorajadas por algumas práticas em algumas escolas que muito ambiciosamente e muito corajosamente buscaram encontrar maneiras de criar uma comunidade de alunos jovens e pensantes capazes de se engajar com esses vastos discursos históricos e políticos de uma maneira que verdadeiramente vem mudar o contexto de vida deles, as interaçóes que eles têm com os professores, com os seus pais, com os seus pares de classe, para mudar os seus contextos locais. Isso pode vir a mudar o contexto comunitário mais amplo, em termos de melhorar as relaçóes intergrupo dentro de uma comunidade local particular e pode, em algum sentido, alimentar esses discursos mais amplos. Eu acredito que algumas escolas têm os recursos, o insight, a energia, têm suas próprias experiências para fazer isso, para ver a si próprias como agentes na construção da cidadania, da comunidade, da sociedade, da nação e também para ver que todos os estudantes individualmente podem ser agentes. Algumas das coisas que as escolas têm feito muito concretamente consistem em possibilidades tremendamente empolgantes, mas, como eu já havia dito, nós não podemos ser otimistas ou ingênuos o bastante para acreditar que se trata de algo fácil de se atingir.

Apesar de o referido Handbook náo abordar diretamente as articulaçóes entre a TRS e a Educaçáo, fica patente na entrevista realizada que os constructos oferecidos pela teoria encerram importante potencial para o campo educacional. Tendo em vista o caráter essencialmente propositivo da Educação, os assuntos os quais o livro se dedicou, seja em âmbito teórico-metodológico, quando do debate das matrizes epistemológicas que orientaram a TRS, seja nos desenvolvimentos conceituais (a exemplo das discussóes realizadas acerca de atitudes, comunicação, imagem, memória coletiva, polifasia cognitiva, comunidade, identidade), dáo mostras da possibilidade de operacionalização metodológica para a promoção, em contextos escolares e náo escolares, de transformaçóes eticamente comprometidas.

\section{Referências}

HOWARTH, Caroline; ANDREOULI, Eleni. 'Changing the context': tackling discrimination at school and in society. International Journal of Educational Development, USA, n. 41, 2015. p. 184-191. Disponível em: <http://www. sciencedirect.com/science/article/pii/S0738059314000510>. Acesso em: 1 set. 2016.

HOWARTH, Caroline; CORNISH, Flora; GILLESPIE, Alex. Making community: diversity, movement and interdependence. In: SAMMUT, Gordon 
et al. (Ed.). The Cambridge Handbook of Social Representations. Cambridge: Cambridge University Press, 2015. p. 179-190.

SAMMUT, Gordon et al. (Ed.). The Cambridge Handbook of Social Representations. Cambridge: Cambridge University Press, 2015. 481 p. 